\title{
Conference Photo
}

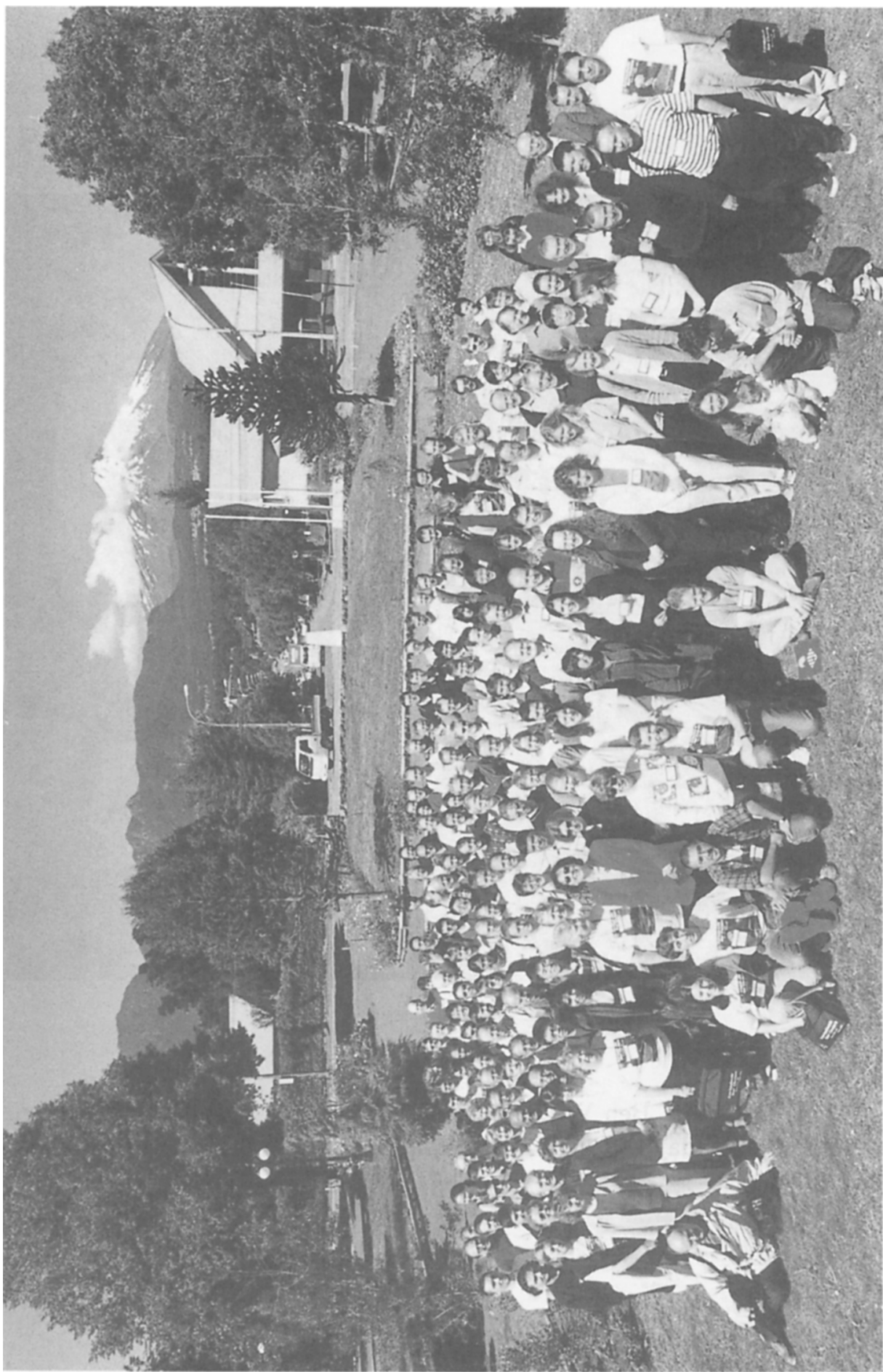




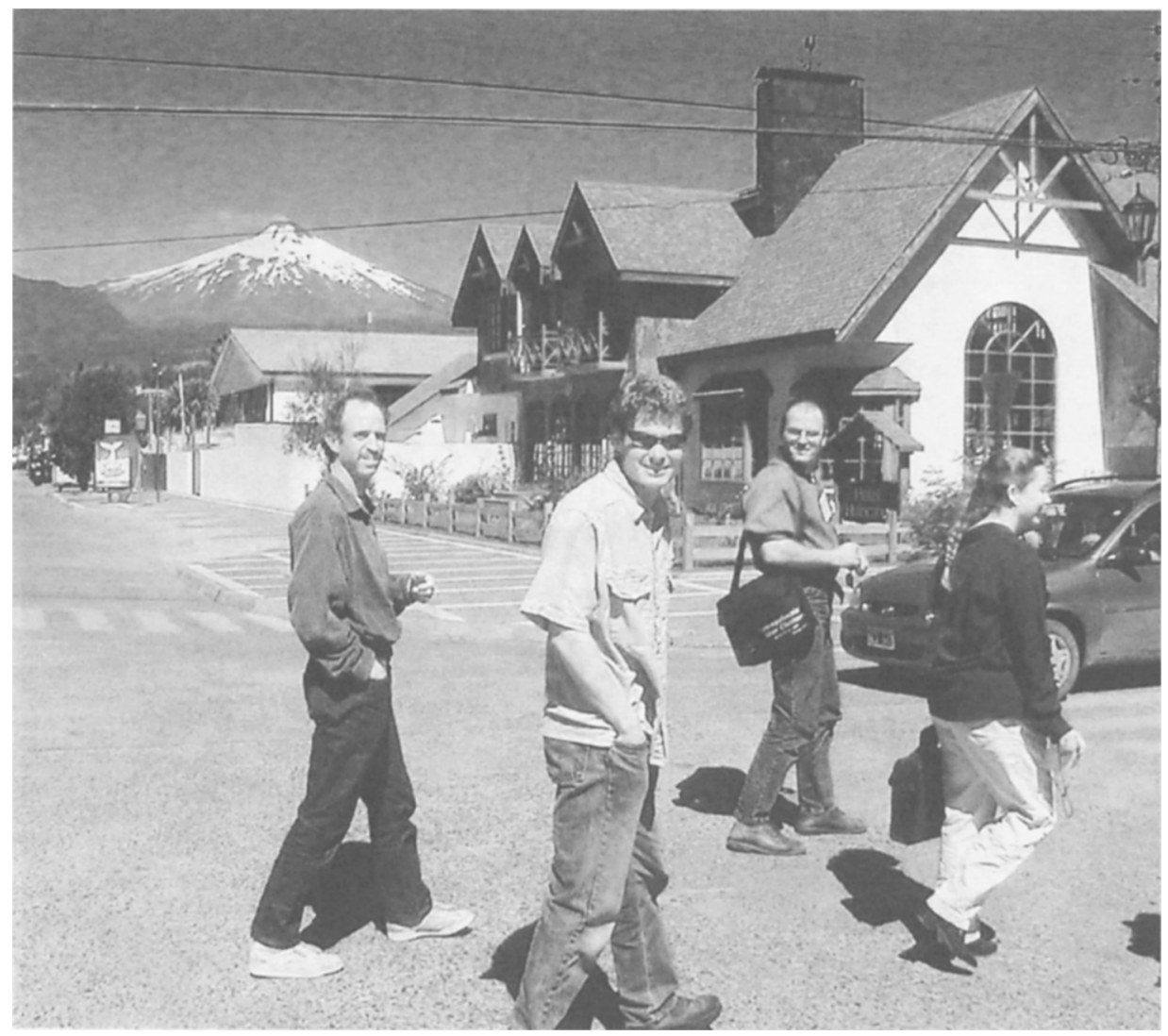

Jon Holtzman, Ben Williams, Boris Dirsch and Jennifer Johnson enjoy a beautiful day in Pucon, with Volcan Villarica looming in the background. 